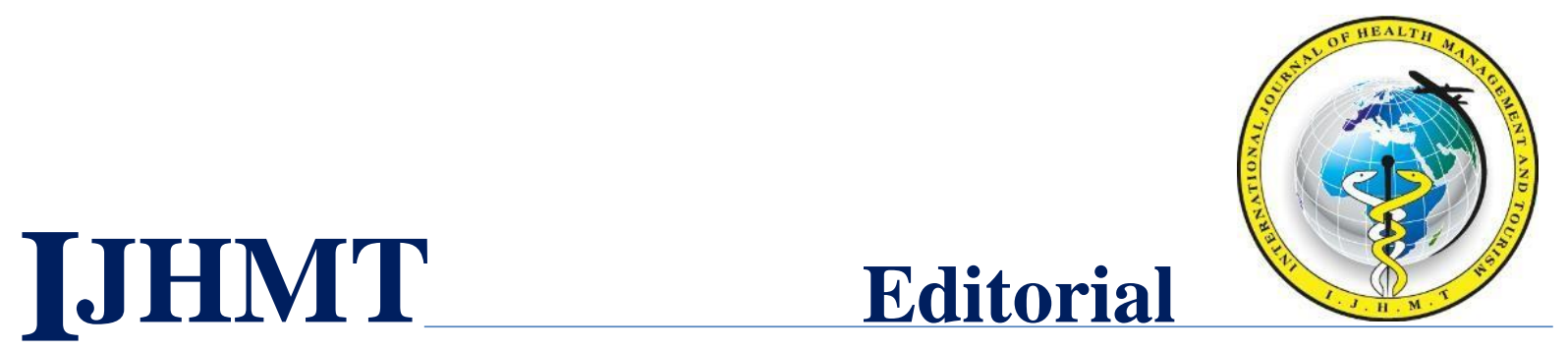

Internatıonal Journal Of Health Management And Tourism

\title{
THE RELATIONSHIP BETWEEN MACROECONOMIC FACTORS AND CHILD HEALTH: AN ECONOMETRIC ANALYSIS
}

\section{Ümit ÇIRAKLI*®e}

\author{
Department of Health Management, Yozgat Bozok University, Turkey \\ E-mail: cirakli@hacettepe.edu.tr \\ ORCID Number: 0000-0002-3134-8830
}

Received: 10.01 .2020

Accepted: 28.04.2020

Research Article

Abstract: The aim of this study is to reveal the relationship between macroeconomic factors and child health and also whether the changes in macroeconomic factors affect child health in Turkey. In this study, real GDP, unemployment, inflation, under-one-mortality and under-five mortality rates between 1974 and 2015 in Turkey were examined using the ARDL (Autoregressive Distributed Lag) bounds testing approach. As a result of the study, it is concluded that economic growth in terms of real GDP has an adverse effect on child health. Also, it is concluded that economic crises have positive effects on children's health as well as negative effects. This study investigated the relationship between macro economy and child health. The results of the study provide evidence that economic growth may adversely affect child health. This study also provides some clues for policymakers to protect child health from negative effects of economic crises. It is suggested that maternity leaves and financial benefits should be increased to protect child health from the negative effects of economic fluctuation. It is also important to increase the food support to poor families in times of economic crisis.

Keywords: Macroeconomic factors, child health, economic crisis, ARDL bounds testing. 


\section{Introduction}

It is known fact that economic factors including income are the important determinants of health. In this respect, the change in macroeconomic factors is likely to have positive or negative effects on health. Human income may be adversely affected by the decline in income due to the economic crises (Tangcharoensathien et al., 2000). In this context, the impact of macroeconomic changes on vulnerable children becomes particularly high (UNICEF 1991).

Improvements in economic factors have positive effects on health in general. The increase in household income facilitates the financing of health care needs. Again, the decrease in unemployment in family members prevents the loss of employment based health insurance and enables the provision of health care needs (HPC - Healthy Public Policy, 2009). Economic growth and increased income, unemployment and poverty alleviation contribute to health by improving the conditions of nutrition, housing and sanitation (HPC, 2009). Improvements in economic conditions positively affect households in terms of health, and create a positive environment for health systems as a result of the increase in public resources. Crisis periods may cause interruptions in spending in many areas, including health services (Thomas et al., 2013). These interruptions in health services affect the quality and availability of health services (Christian, 2009; Tangcharoensathien et al., 2000). In this context, it is easier for individuals to have access to public health services when economy is good.

It is also stated that improvements in the economy may adversely affect health and even economic crisis periods can positively affect health (Gertham and Ruhm, 2006; Granados, 2005; Mattei et al., 2014; Neumayer, 2004; Ruhm, 2003). Granados (2005) states that economic growth in economic cycles has a negative impact on mortality rates in general. One of the important points that Granados (2005) focuses on is the increase in stress levels during the economic growth periods and the negative effects of stress related problems on health. Another point is the increase of alcohol and smoking in the economic expansion stages and the increase in the use of vehicles, the decrease of physical exercise, such as the increase of harmful behaviors (Granados 2005). Similarly, Ruhm (2003), Gertham and Ruhm (2006), McClure et al. (2012) argue that health hazards may increase in economic growth periods and, health promoting behaviors may increase in times of economic crisis. On the other hand, according to Lopes (1934), it is doubtful that people who are unemployed in times of economic crisis will be able to carry out activities useful to health as a regular habit. Because the unemployed person is most likely to devote most of his time to job search. Moreover, it is 
not possible to benefit the long time spent in adverse environments due to the decrease in living standards during the crisis periods. In addition, the decrease in family income generally means that the woman needs to work more (Lopes, 1934). Since health-related data are usually caused by time delay, it is not possible to fully assess the health impact of the crisis in the short term (Stuckler et al., 2011; Tangcharoensathien et al., 2000). The long-term effect of income is protective of health and negatively correlated with mortality rates (Cutler et al., 2000). When unemployment increases, alcohol consumption may be reduced due to loss of income and alcohol consumption may increase due to increased leisure time and stress. However, in the 1990s, when privatization was fast and layoffs were high, there was an increase in excessive drinking and death rates in Russia despite the prohibition of drinking (Menabde, 2009).

The number of studies examining the relationship between macroeconomic factors and child health is limited. Rather, studies focus on the health effects of adverse factors caused by economic crises such as unemployment, job insecurity, stress increase and loss of income. In most of these studies, economic crises appear to have a negative effect on child health (Cader and Perera, 2011; Cutler et al., 2000; Paxson and Schady, 2004; UNICEF, 1991). On the other hand, there are very few studies on the fact that economic crises do not have a significant impact on maternal and infant health (Borowy, 2011; Schady and Smitz, 2010). However, these studies draw attention to the severity of the crisis (Schady and Smitz, 2010) and the importance of measures to prevent the effects of the economic crisis on maternal and infant health (Borowy, 2011).

The aim of this study is to determine the relationship between macroeconomic factors and child health and whether the changes in macroeconomic factors affect child health. In this context, real GDP, unemployment, inflation, under-one-mortality rate (infant mortality rate) and under-five mortality rate data between the years 1974-2015 were analyzed using the ARDL (Autoregressive Distributed Lag) bounds testing approach. In the study, under-one mortality rate (infant mortality rate) and under-five mortality rate were used as child health indicators and dependent variables, while macroeconomic indicators (inflation, real GDP and unemployment) were included as independent variables. The economic crises of 1994, 2001 and 2009 were included in the models as dummy variables. EViews 9.5 package program was used to analyses the data obtained from the study with ARDL bounds test. 


\section{Method}

\subsection{Study Design}

In this study, ARDL bounds testing approach was used to determine the relationship between macroeconomic factors and child health. On the basis of the cointegration analysis developed for the determination of long-term relationships between time series and variables, the stationary degrees of the series lie. In this context, if all variables are stationary $\mathrm{I}(0)$, the model can be estimated by ordinary least squares (OLS) technique (Ciftci and Yildiz, 2015). The ARDL bounds test approach developed by Pesaran et al. (2001) does not require all explanatory variables to be I (1). Therefore, it is not obligatory to test whether the variables have a unit root in the ARDL approach (Pesaran et al., 2001). On the other hand, there is a requirement that the dependent variable in the model is I (1) and that none of the variables planned to be used in the analysis is I (2). Because the lower and upper critical values given by Pesaran et al. (2001) were obtained according to the status of series I (0) and I (1). Therefore, in order to ensure that at least these conditions are met, unit root tests should be performed before ARDL approach is used and it is useful to determine the stationary degrees of the series (Ciftci and Yildiz, 2015).

\subsection{Data}

The data of the study were obtained annually as a total of 42 observations between the years 1974-2015 for Turkey. In the study, infant and under five mortality rates were included as child health indicators and dependent variables. Real GDP, unemployment and inflation rates were used as macroeconomic indicators and independent variables. In addition to these data, the economic crises of 1994, 2001 and 2009 were included in the models as dummy variables. The coding of these variables was realized by assigning 1 to the negative real GDP years and 0 to the others.

Table 1. Data, Abbreviations and Data Source

\begin{tabular}{lcc}
\hline \multicolumn{1}{c}{ Data } & Abbreviation & Data Source \\
\hline Under-one-mortality rate (per thousand) & U1MR & World Bank (2016) \\
\hline Under-five-mortality rate (per thousand) & U5MR & World Bank (2016) \\
\hline Real GDP & RGDP & World Bank (2016) \\
\hline Unemployment rate & UNP & $\begin{array}{c}\text { TurkStat (2016), } \\
\text { Bulutay (1995) }\end{array}$ \\
\hline Inflation rate & INF & World Bank (2016) \\
\hline
\end{tabular}




\subsection{Statistical Analysis}

The EViews 9.5 statistical program was used to perform the ARDL cointegration method. The ARDL method was carried out in four stages. First, a unit root test was applied for time series. Augmented Dickey-Fuller (ADF) - Extended Dickey-Fuller test was used for unit root test (Ciftci and Yildiz, 2015). In the second stage, an Unrestricted Error Correction Model (UECM) was established and the model was estimated by OLS (Least squares) technique and a border test (wald test) was performed. The value of the F statistic obtained as a result of the Wald test was determined by Pesaran et al. (2001) compared with the upper and lower critical values derived from the variables were determined whether there is a cointegration relationship between the variables. Akaike information criterion was used to calculate the optimal lag length for each variable in the UECM. In the determination of the maximum lag length to be determined for the predicted model, the length of delay in which there is no autocorrelation problem is taken into consideration. The autocorrelation problem was determined by Breusch-Godfrey autocorrelation LM test. In addition, under the diagnostic tests of the selected model, the Jarque-Bera test for conformity to the normal distribution, the ARCH test for changing variance, or the Ramsey Reset test for the functional form error. In addition, CUSUM and CUSUM-SQ tests were performed to determine the stability of the model. In the third stage, the ARDL model was estimated to determine the long-term coefficients. Akaike information criterion was used to determine the maximum lag length. For the predicted model, Breusch-Godfrey autocorrelation LM test, Jarque-Bera normality test, ARCH changing variance test, Ramsey Reset model build error test and CUSUM and CUSUM-SQ stability tests were performed. In the fourth stage, Error Correction Model (ECM) was created by using ARDL model and this model was estimated by using OLS technique.

\subsection{Limitations and Assumptions}

The data obtained for our study was accepted to be correct. Another important limitation of our study is the number of observations. The data obtained in our study consisted of 42 observations that can be obtained on an annual basis. Considering the time series analysis, it can be assumed that this number is small. 


\section{Results and Discussions}

\subsection{Unit root test results}

ADF unit root test was used to determine the stability of the time series used in the analysis.

Table 2 shows the ADF unit root test results for the corresponding time series. In the unit root tests, the logarithmic transformed values of the under-one and under-five mortality rate series are in no case I (1), so the results of the logarithmic untransformed values are given in Table 2. According to the ADF unit root test results shown in the Table 2, the analysis was carried out with a constant and trendy model, since the only model with constant and trend together in the under-one mortality rate and under-five mortality rate series provided the condition that the dependent variable was not $\mathrm{I}(0)$ and $\mathrm{I}(1)$ being the condition.

Table 2. Unit root test results

\begin{tabular}{|c|c|c|c|c|c|}
\hline \multirow{2}{*}{ Variables } & \multirow{2}{*}{ Models } & \multicolumn{2}{|c|}{ Level Values } & \multicolumn{2}{|c|}{ First Difference Values } \\
\hline & & $\mathbf{t}$ & $\mathbf{p}$ & $\mathbf{t}$ & $\mathbf{p}$ \\
\hline \multirow{3}{*}{ RGDP } & Constant & 2.19 & 0.999 & $-5.53 * * *$ & 0.000 \\
\hline & Constant and Trend & -0.83 & 0.953 & $-6.31 * * *$ & 0.000 \\
\hline & None & 6.05 & 0.999 & $-3.64 * * *$ & 0.000 \\
\hline \multirow{3}{*}{ INF } & Constant & -1.95 & 0.304 & $-7.49 * * *$ & 0.000 \\
\hline & Constant and Trend & -2.45 & 0.346 & $-7.57 * * *$ & 0.000 \\
\hline & None & -1.15 & 0.222 & $-7.59 * * *$ & 0.009 \\
\hline \multirow{3}{*}{ UNP } & Constant & -2.17 & 0.219 & $-5.47 * * *$ & 0.000 \\
\hline & Constant and Trend & -2.48 & 0.334 & $-5.40 * * *$ & 0.000 \\
\hline & None & 0.15 & 0.724 & $-5.52 * * *$ & 0.000 \\
\hline \multirow{3}{*}{ U5MR } & Constant & $-5.81 * * *$ & 0.000 & -1.11 & 0.700 \\
\hline & $\begin{array}{c}\text { Constant and } \\
\text { Trend }\end{array}$ & -1.62 & 0.764 & $-4.35 * * *$ & 0.007 \\
\hline & None & $-6.93 * * *$ & 0.000 & $-2.76 * * *$ & 0.007 \\
\hline \multirow{3}{*}{ U1MR } & Constant & $-4.03 * * *$ & 0.003 & 1.22 & 0.997 \\
\hline & $\begin{array}{c}\text { Constant and } \\
\text { Trend }\end{array}$ & -2.10 & 0.522 & $-3.46^{*}$ & 0.057 \\
\hline & None & $-5.90 * * *$ & 0.000 & $-4.18 * * *$ & 0.000 \\
\hline
\end{tabular}

Note: * 10\% significance level, $* * 5 \%$ significance level, $* * * 1 \%$ significance level.

\subsection{Unrestricted Error Correction Model Results (ARDL Bounds Testing)}

The UECM models, which include dummy variables, are prepared as follows: infant mortality rate, inflation rate, real GDP and unemployment.

$$
\begin{aligned}
& \Delta \mathrm{U}_{1 M \mathrm{MR}_{t}}=\alpha+\delta t+\sum_{i=1}^{m} \lambda_{1 i} \Delta \mathrm{U}_{1} \mathrm{MR}_{\mathrm{t}-\mathrm{i}}+\sum_{i=0}^{n} \lambda_{2 i} \Delta \mathrm{INF}_{\mathrm{t}-\mathrm{i}}+\sum_{i=0}^{p} \lambda_{3 i} \Delta \mathrm{RGDP}_{\mathrm{t}-\mathrm{i}}+\sum_{i=0}^{q} \lambda_{4 i} \Delta \mathrm{UNP}_{\mathrm{t}-\mathrm{i}} \\
& +\gamma_{1} \mathrm{U}_{1 \mathrm{MR}} \mathrm{t-1}+\gamma_{2} \mathrm{INF}_{\mathrm{t}-1}+\gamma_{3} \mathrm{RGDP}_{\mathrm{t}-1}+\gamma_{4} \mathrm{UNP}_{\mathrm{t}-1}+\gamma_{5} \mathrm{~d}_{-} 1994 \\
& +\gamma_{6} \mathrm{~d}_{-} 2001+\gamma_{7} \mathrm{~d} \_2009+\varepsilon_{t}
\end{aligned}
$$




$$
\begin{aligned}
\Delta \mathrm{U}_{5 M R}=\alpha & +\delta t \sum_{i=1}^{m} \lambda_{1 i} \Delta \mathrm{U}_{\mathrm{t}}=\mathrm{MR}_{\mathrm{t}-\mathrm{i}}+\sum_{\mathrm{i}=0}^{\mathrm{n}} \lambda_{2 \mathrm{i}} \Delta \mathrm{INF}_{\mathrm{t}-\mathrm{i}}+\sum_{\mathrm{i}=0}^{\mathrm{p}} \lambda_{3 \mathrm{i}} \Delta \mathrm{RGDP}_{\mathrm{t}-\mathrm{i}}+\sum_{\mathrm{i}=0}^{\mathrm{q}} \lambda_{4 \mathrm{i}} \Delta \mathrm{UNP}_{\mathrm{t}-\mathrm{i}} \\
& +\gamma_{1} \mathrm{U} 5 \mathrm{MR}_{\mathrm{t}-1}+\gamma_{2} \mathrm{INF}_{\mathrm{t}-1}+\gamma_{3} \mathrm{RGDP}_{\mathrm{t}-1}+\gamma_{4} \mathrm{UNP}_{\mathrm{t}-1}+\gamma_{5} \mathrm{~d}_{-} 1994 \\
& +\gamma_{6} \mathrm{~d}_{-} 2001+\gamma_{7} \mathrm{~d}_{-} 2009+\varepsilon_{\mathrm{t}}
\end{aligned}
$$

In the above equations, the term $\alpha$ refers to the constant component of the model, $\delta$ t for the trend component of the model, the term $\Delta$ for the first difference processor, and the term $\varepsilon$ is for the constant error with white noise. An UECM model with a maximum lag length is estimated by the model ( $\mathrm{m}, \mathrm{n}, \mathrm{p}, \mathrm{q}$ ). The F test (wald test) was used for the bounds testing of the model and the obtained $\mathrm{F}$ test value was compared with the lower and upper critical values in Table CI (iv) of Pesaran et al. (2001). Table 3 presents the estimation results for the Unrestricted Error Correction Model.

According to the information in Table 3, the obtained $F$ test values $(7,12$ and 7,28) are above the critical values of the upper limit given in Table CI (iv) by Pesaran et el. (2001); the existence of co-

\begin{tabular}{|c|c|c|c|c|c|c|}
\hline $\begin{array}{l}\text { Dependent } \\
\text { Variable }\end{array}$ & Estimated ARDL Model & $\mathbf{k}$ & $\mathbf{F}$ & $\mathbf{p}$ & $\mathbf{R}^{2}$ & $A-R^{2}$ \\
\hline U1MR & {$[2,1,2,0]$} & 3 & 7.12 & 0,000 & 0,998 & 0,996 \\
\hline Diagnostic tests* & \multicolumn{6}{|c|}{$\begin{array}{l}\text { SE: 0.056; SSE: 0.071; S.C.: 0.87, p: 0.433; J.-B.Nor.: 2.97, p: 0.226; Het.: } \\
\text { 0.007, p: 0.930; F.Res: 1.49, p: } 0.234\end{array}$} \\
\hline $\begin{array}{l}\text { Dependent } \\
\text { Variable }\end{array}$ & Estimated ARDL Model & $\mathbf{k}$ & $\mathbf{F}$ & $\mathbf{p}$ & $\mathbf{R 2}$ & D-R2 \\
\hline U5MR & {$[2,0,0,4]$} & 3 & 7.28 & 0.000 & 0.9989 & 0.9980 \\
\hline Diagnostic tests* & \multicolumn{6}{|c|}{$\begin{array}{l}\text { SE: } 0.075 \text {; SSE: 0.107; S.C.: 2.08, p: 0.133; J.-B.Nor.: 0.79, p: 0.673; Het.: } \\
\text { 2.42, p: 0.128; F.Res: 2.34, p: } 0.143\end{array}$} \\
\hline Critical Values & \multicolumn{6}{|c|}{$\begin{array}{l}\text { \%1: lower limit } 4.30 \text { - upper limit 5.23; \% 2.5: lower limit } 3.80-\text { upper limit } \\
\text { 4.68; \%5: lower limit } 3.38 \text { - upper limit 4.23; \%10: lower limit } 2.97 \text { - upper } \\
\text { limit } 3.74 \text {. }\end{array}$} \\
\hline
\end{tabular}
integration between inflation and real GDP and unemployment is understood.

Table 3 ARDL Bounds Testing Estimation Results

* Meaning of Abbreviations in the section of Diagnostic Tests; SE: Standard Error, SSE: Sum of Squared Errors, S.C .: Breusch-Godfrey LM autocorrelation test, J.-B.Nor .: JarqueBera normality test, Het .: ARCH test, F.Res .: Ramsey Reset test.

In terms of diagnostic statistics (autocorrelation problem, normal distribution, heteroscedasticity problem and model misspecification error) there is no problem. In addition, according to the CUSUM and CUSUM-SQ graphs of Figure 1, the coefficients of the model are stable. 
Figure 1: UECM CUSUM and CUSUM-SQ Graphs: Infant Mortality Rate
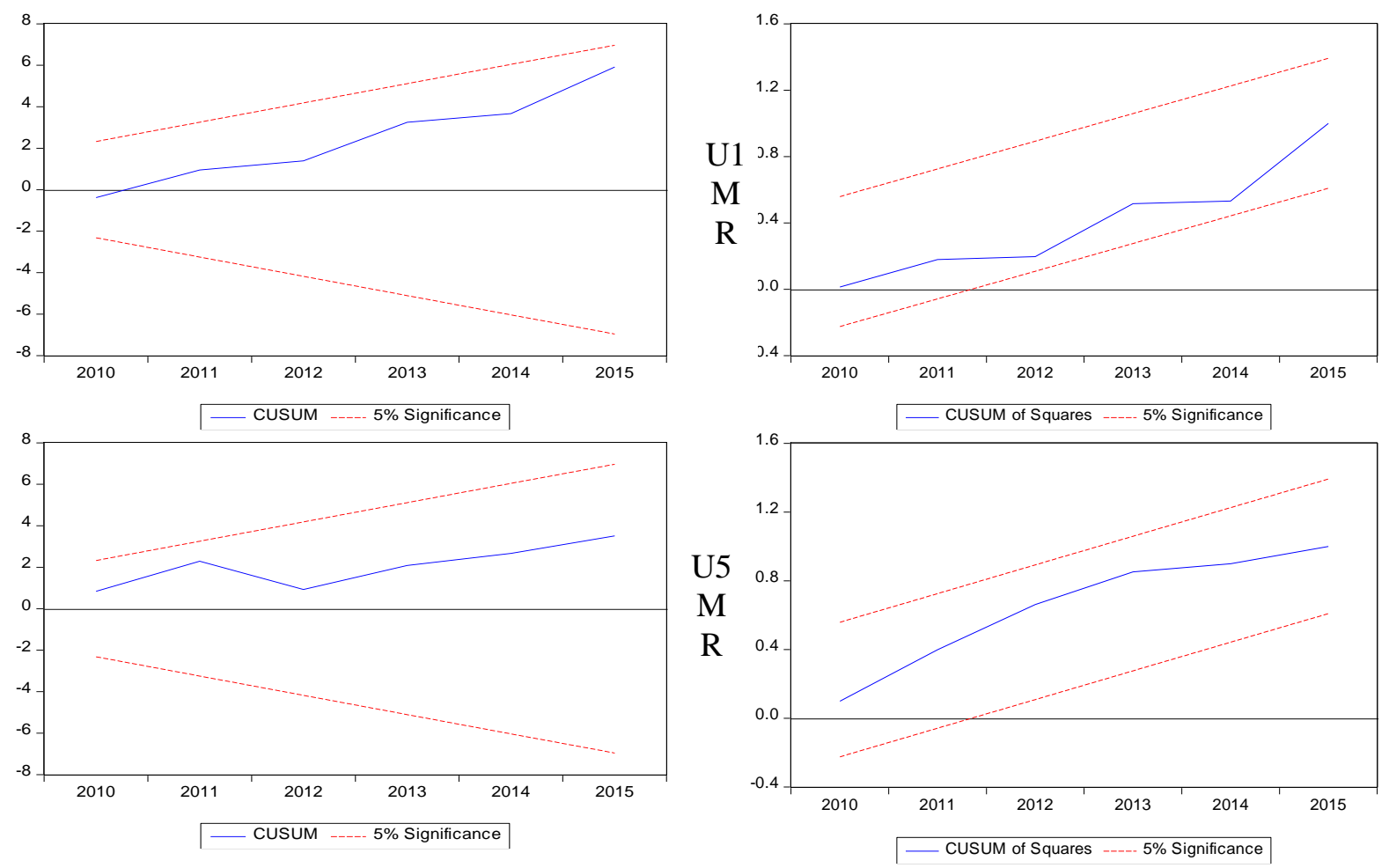

\subsection{ARDL Model Long-and Short-Term Coefficients Estimation Results}

\subsubsection{Under-One Mortality Rate Results}

With the test results of the UECM, it was decided to establish a suitable ARDL model and long-term coefficients after the decision on cointegration relation was found in the model under-one-mortality. In this context, a general ARDL model with the Eviews 9.5 package program was estimated by taking the maximum lag length 4 and by using the Akaike information criterion in the selection of the most appropriate lag length by the OLS technique. According to the estimation results, ARDL [2, 2, 2, 4] model was decided to be the most suitable model*. After estimating the long-term coefficients of the ARDL model, an error correction model was created to estimate the short-term coefficients. This model is also estimated by the ordinary least squares' technique. Table 4 shows the predicted long and short term forecast results and diagnostic statistics of the ARDL [2, 2, 2, 4] model. 
Table 4. ARDL Model Long and Short-Term Estimation Results

Estimated ARDL Model: $[2,2,2,4]$

Long Term Model: Dependent Variable: U1MR

Short Term Model (ECM):

Dependent Variable: $\triangle \mathrm{U} 1 \mathrm{MR}$

\begin{tabular}{|c|c|c|c|c|c|c|c|}
\hline \multirow[b]{2}{*}{ Variables } & \multirow[b]{2}{*}{ Coefficient } & \multirow[b]{2}{*}{ t-statistics } & \multicolumn{5}{|c|}{ Coefficien } \\
\hline & & & $\mathbf{p}$ & Variables & $\mathbf{t}$ & t-statistics & $\mathbf{p}$ \\
\hline INF & 0.118 & 1.842 & 0.080 & $\Delta$ U1MR(-1) & 0.482 & $6.129 * * *$ & 0.000 \\
\hline RGDP & 0.000 & $6.126 * * *$ & 0.000 & $\Delta \mathbf{I N F}$ & 0.000 & 0.055 & 0.956 \\
\hline$\overline{\text { UNP }}$ & 1.883 & 2.029 & 0.056 & $\Delta \mathrm{INF}(\mathbf{- 1})$ & -0.001 & $-2.460 * *$ & 0.023 \\
\hline $\bar{D}$ D_1994 & -2.573 & -0.807 & 0.429 & $\Delta$ RGDP & 0.000 & $2.322 * *$ & 0.030 \\
\hline$\overline{\text { D_2001 }}$ & 7.129 & $2.090 * *$ & 0.049 & $\Delta$ RGDP(-1) & -0.000 & -1.571 & 0.131 \\
\hline$\overline{\text { D_2009 }}$ & -7.394 & -1.775 & 0.091 & $\Delta \mathbf{U N P}$ & 0.041 & $3.107 * * *$ & 0.005 \\
\hline \multirow[t]{8}{*}{ Trend } & -3.031 & $-6.059 * * *$ & 0.000 & $\Delta \mathbf{U N P}(-1)$ & 0.012 & 0.979 & 0.339 \\
\hline & & & & $\Delta \operatorname{ISSIZ(-2)}$ & 0.028 & $2.997 * * *$ & 0.007 \\
\hline & & & & $\Delta I S S I Z(-3)$ & 0.016 & 1.775 & 0.091 \\
\hline & & & & $\Delta D \_1994$ & -0.053 & -1.156 & 0.261 \\
\hline & & & & $\Delta D \_2001$ & 0.183 & $3.711 * * *$ & 0.001 \\
\hline & & & & $\Delta D \_2009$ & -0.135 & $-2.492 * * *$ & 0.021 \\
\hline & & & & $\mathrm{C}$ & -0.576 & $-5.666 * * *$ & 0.000 \\
\hline & & & & $\operatorname{ECM}(-1)$ & -0.024 & -6.647 & 0.000 \\
\hline
\end{tabular}

$\overline{\mathbf{E C M}}=$ U1MR $-\left(0.1182 * \mathrm{INF}+0.0000 * \mathrm{RGDP}+1.8831 * \mathrm{UNP}-2.5739 * \mathrm{D} \_1994+7.1296 * \mathrm{D} \_2001\right.$

-7.3941*D_2009-3.0317*@TREND )

Diagnostic tests: $\mathbf{R}^{2}$ : 0.998; A-R ${ }^{2}$ : 0.996; SE: 0.053; SSE: 0.56; S.C.: 0.66, p: 0.424; J.-B.Nor.:

3.09, p: 0.212; Het.: 0.01, p: 0.892; F.Res: 0.88, p: 0.385

Note: Meaning of Abbreviations in the section of Diagnostic Tests; $\mathrm{R}^{2}$ : Determination Factor; A-R ${ }^{2}$ : Adjusted Determination Factor; SE: Standard Error, SSE: Sum of Squared Errors, S.C.: Breusch-Godfrey LM autocorrelation test, J.-B. Nor.: Jarque-Bera normality test, Het .: ARCH test, F.Res .: Ramsey Reset test

It is understood that the ARDL [2, 2, 2, 4] model, which is estimated according to the information in Table 4, does not have any problems in terms of diagnostic statistics (autocorrelation, normal distribution, heteroscedasticity and model misspecification error). In addition, according to CUSUM and CUSUM-SQ graphs (Figure 2), it is understood that the long-term coefficients obtained from the ARDL bounds test did not exceed the critical values at $5 \%$ meaning in any period and the coefficients of the model were stable. 
Figure 2. ARDL CUSUM and CUSUM-SQ Graphs: Infant Mortality Rate
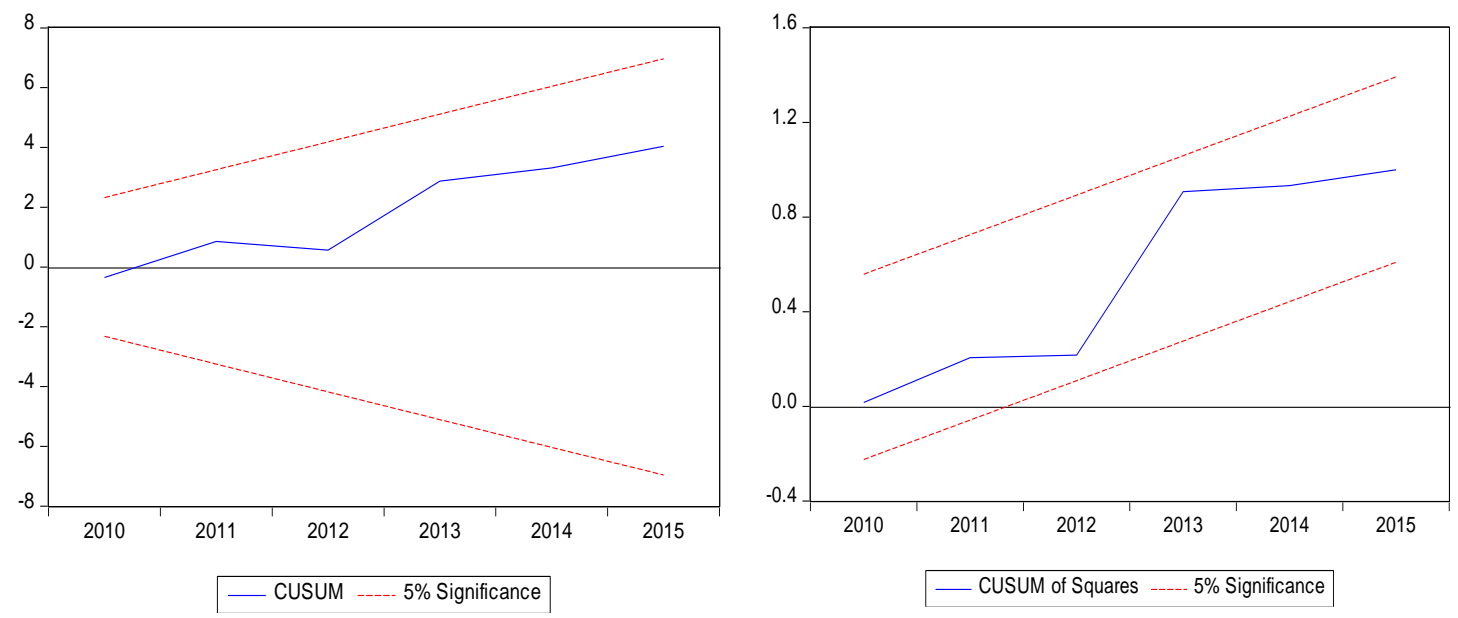

Table 4 shows that the long-term coefficient of the inflation rate (0.118) is statistically significant at $90 \%$ confidence level $(\mathrm{p}=0.080)$. From this result, it is possible to say the long-term increase in the inflation rate adversely affects the under-one-mortality. The fact that infants become more dependent on their mothers in the first year after birth, especially in terms of breast milk, may cause their mothers to be affected more than their mothers' health.

When the long-term relationship between infant mortality rate and real GDP is examined, it is observed that the coefficient of Real GDP is statistically significant $(p=0.000)$. In other words, the increase in real GDP affects the under-one-mortality or in other words the health of infants in negatively. As stated by some authors, income growth may in some cases lead to an increase in harmful behaviors such as alcohol and cigarette consumption, unhealthy nutrition, more work, and ultimately to decrease social interaction or the time required for health care needs (Gertham and Ruhm, 2006; McClure et al., 2012; Riva et al., 2011; Ruhm, 2003). As a result of this situation, long-term income growth may cause mothers to not have enough time for babies and provide them with insufficient care. On the other hand, if the mothers develop health hazards behaviors, the health of their babies will be affected naturally. As a result of this correct relationship between real GDP and infant mortality rate, it is considered that the increase in income may have caused health hazards behavior for the mother or may have reduced the time needed to care for the baby.

When the long-term relationship between infant mortality rate and unemployment is examined, it is seen that the coefficient of unemployment rate (1.883) is statistically significant $(\mathrm{p}=0.056)$. With this result, it is possible to say that there is a negative 
relationship between unemployment and infant mortality rate in long term. Because the positive coefficient means that infant mortality rises when unemployment rises. Therefore this result can be interpreted as negative situation or effect. The reason for this negative effect of unemployment on infant health is evaluated as the mother's job search due to unemployment in her family members and the fact that she cannot provide good care by allocating less time to the baby.

According to the results of the error correction model in Table 4, it is seen that the coefficient of ECM (-1) is negative and statistically significant as expected. After the shocks that may occur in the system in the short term, we can say that the deviations in the long-term equilibrium of the system will be eliminated in $2.4 \%$, after a period, in other words, we can say that the process of imbalance is slow.

From the results given in Table 4, we can see that the current value of the inflation rate affects the infant mortality rate in the right direction (negative) in a similar way to the long-term, but it is understood that this relationship is not statistically significant. On the other hand, the oneyear lagged value of the inflation rate affects the infant mortality rate in the opposite (positive) direction $(-0.001)$ and statistically significant $(\mathrm{p}=0.023)$ in contrast to the longterm.

For the short-term relationship between infant mortality rate and real GDP, we see a significantly negative effect the current value of real GDP on the infant mortality rate. In other words, the current value of the increase in real GDP adversely affects the infant mortality rate. One term lagged value of real GDP has decreasing, in other words, positive affect on infant mortality rate, but this relationship was not statistically significant ( $p>0.10$ ).

When the relationship between infant mortality rate and unemployment is examined, it is observed that there is a positive correlation between the two variables in the short term, but the coefficient of current, two and three periods of delayed values is not statistically significant. In other words, it is possible to say that the increase in unemployment rate adversely affects the infant mortality rate under the age of one, in the two and three periods delayed results. From this result, it is thought that babies are affected indirectly by the possible negative effects of unemployment's increase on maternal health.

When the effects of economic crises on the infant mortality rate year are analyzed, it is seen that the economic crisis of 1994 does not have a statistically significant effect on the infant 
mortality rate according to the information in Table 4. It is observed that the 2001 economic crisis affected infant mortality rate in the right direction (0.183) and statistically significant ( $\mathrm{p}$ $=0.001)$. It is understood that the 2009 economic crisis affected the infant mortality rate year in the opposite direction $(-0.135)$ and statistically significant $(p=0.021)$. From these results, it is possible to say that the 1994 crisis did not affect the infant mortality rate and the 2001 crisis affected negatively, the 2009 crisis affected positively.

There may be a variety of reasons that the 2001 crisis has a negative impact on the infant mortality rate, and the 2009 economic crisis has a positive impact on the infant mortality rate. Since the 2001 economic crisis was more severe, mothers had to start working and did not provide adequate time-intensive activities for the babies. Breastfeeding, which is one of these activities and which is very important for baby health, may negatively affect infant health due to mother's work. Similarly, although free of charge, due to external costs such as transportation, the health care needs of the baby, such as postpartum control and follow-up, vaccination, may not be adequately met. Moreover, public health expenditures may have an impact on the significant impacts of the 2001 and 2009 economic crises on infant mortality, as Fernandez and Lopez-Calva (2009) point out. As a result, in the different significant effects of the economic crises of 2001 and 2009, in the 2001 economic crisis, as Schady and Smitz (2010) stated, the substitution effect prevailed, the decrease in the useful time-intensive activity for the baby, the lack of adequate health care needs, the decrease in public health expenditures and the severity of the crisis can be effective.

\subsubsection{Under-Five Mortality Rate Results}

For the under-five mortality rate, a general ARDL model with the Eviews 9.5 package program was estimated by taking the maximum lag length 4 and by using the Akaike information criterion in the selection of the most appropriate lag length by the OLS technique. According to the estimation results, $\operatorname{ARDL}[3,0,0,0]$ model was decided to be the most suitable model. After estimating the long-term coefficients of the ARDL model, an error correction model was created to estimate the short-term coefficients and the coefficients of the model were estimated with the least-squares technique. Table 5 shows the long and short term prediction results and diagnostic statistics of the ARDL $[3,0,0,0]$ model. 
Table 5. ARDL Model Long and Short Term Estimation Results

Estimated ARDL Model: $[3,0,0,0]$

Long Term Model: Dependent Variable: U5MR

Short Term Model (ECM): Dependent Variable:

$\triangle \mathrm{U} 5 \mathrm{MR}$

\begin{tabular}{|c|c|c|c|c|c|c|c|}
\hline Variables & Coefficient & t-statistics & $\mathbf{p}$ & Variables & Coefficient & t-statistics & $\mathbf{p}$ \\
\hline INF & 0.058 & 0.928 & 0.361 & $\Delta \mathrm{INF}$ & 0.000 & 0.831 & 0.412 \\
\hline$\overline{\text { RGDP }}$ & 0.000 & $3.642 * * *$ & 0.001 & $\Delta$ RGDP & 0.000 & $1.971^{*}$ & 0.058 \\
\hline UNP & 1.945 & 1.785 & 0.085 & $\Delta \mathrm{UNP}$ & 0.024 & 1.395 & 0.173 \\
\hline$\overline{D \_1994}$ & 6.233 & 0.956 & 0.346 & $\Delta \mathrm{D} \_1994$ & 0.146 & $2.416 * *$ & 0.022 \\
\hline$\overline{D \_2001}$ & 4.153 & 0.676 & 0.504 & $\Delta D \_2001$ & 0.036 & 0.605 & 0.549 \\
\hline$\overline{\text { D_2009 }}$ & -4.013 & -0.539 & 0.593 & $\Delta \mathrm{D} \_2009$ & -0.008 & -0.117 & 0.907 \\
\hline \multirow[t]{2}{*}{ Trend } & -2.786 & $-2.077 * *$ & 0,047 & Constant & 0.010 & 0.216 & 0.830 \\
\hline & & & & $\operatorname{ECM}(-1)$ & -0.013 & $-6.176^{* * *}$ & 0.000 \\
\hline
\end{tabular}

Diagnostic tests: $\mathbf{R}^{2}$ : 0.997; A-R²: 0.996; SE: 0.077; SSE: 0.168; S.C.: 0.42, p: 0.787; J.-B.Nor.: 0.50, p: 0.777; Het.: 0.86, p: 0.357; F.Res: 0.56, p: 0.459

Note: Meaning of Abbreviations in the section of Diagnostic Tests; $\mathrm{R}^{2}$ : Determination Factor; A-R ${ }^{2}$ : Adjusted Determination Factor; SE: Standard Error, SSE: Sum of Squared Errors, S.C.: Breusch-Godfrey LM autocorrelation test, J.-B. Nor $\therefore$ Jarque-Bera normality test, Het $\therefore$ ARCH test, F.Res .: Ramsey Reset test

It is understood that the ARDL $[3,0,0,0]$ model predicted according to the information in Table 5 does not have any problems in terms of diagnostic statistics (autocorrelation, normal distribution, heteroscedasticity and model misspecification error). According to the CUSUM and CUSUM-SQ graphs in Figure 3, the long-term coefficients obtained from the ARDL bounds test have not exceeded the critical values at 5\% significance level in any period and the coefficients of the model are stable.

Figure 3. ARDL CUSUM and CUSUM-SQ Graphs: Under-Five Mortality Rate
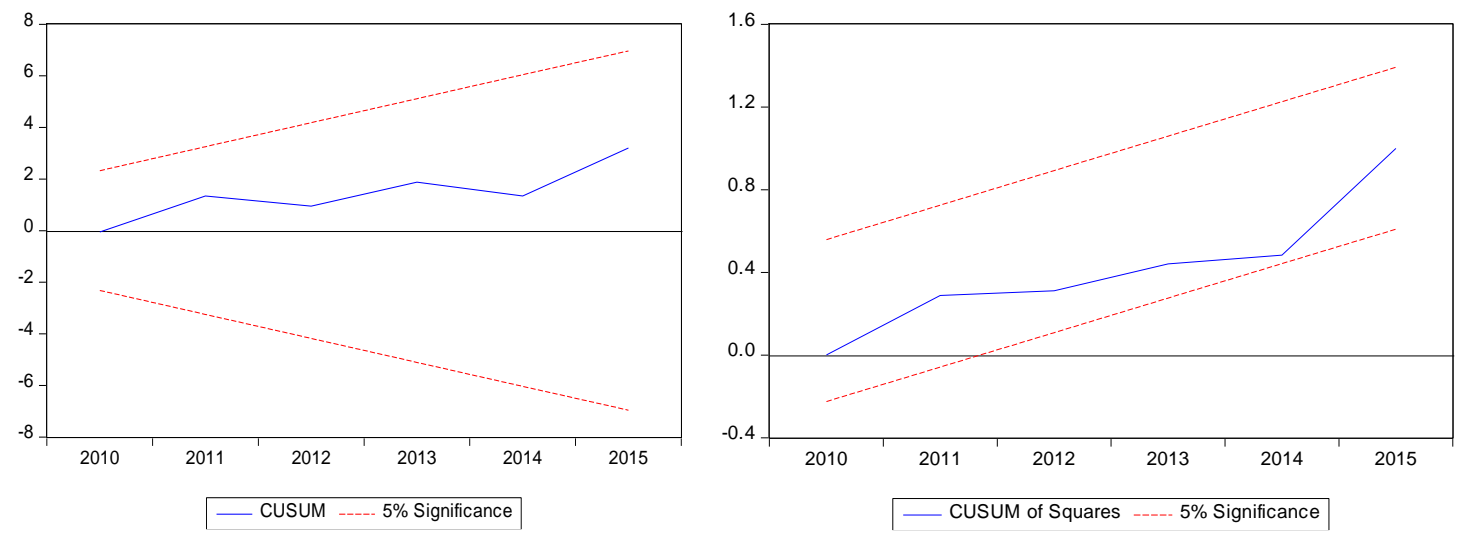
According to the information in Table 5, it is seen that there is no statistically significant relation between long-term inflation rate and under-five mortality rate $(p=0.361)$. From this result, it is possible to say that inflation has not significantly affected under-five mortality rate in the long term. When the long-term relationship between the under-five mortality rate and the real GDP is analyzed, it is seen that the coefficient of real GDP is positive (0.000) and statistically significant $(\mathrm{p}=0.001)$ according to the information in the Table 5. In other words, the increase in real GDP in the long term adversely affects the under-five mortality rate. When the long-term relationship between unemployment and under-five mortality rate is examined, it is determined that this relationship is not statistically significant at $95 \%$ confidence level $(\mathrm{p}>0.05)$.

According to the results of the error correction model in the Table 5, it is seen that the coefficient of ECM (-1) is negative and statistically significant as expected. From the coefficient of the error correction model $(-0,013)$, we can say that $1.3 \%$ of the deviations in the long term balance of the system will be eliminated after a period of shocks that may occur in the system in the short term. In other words, we can say that the process of imbalance is slow.

When the coefficients related to the short-term coefficients in the Table 5 are analyzed, there is a direct relationship between independent variables (inflation rate, real GDP and unemployment rate) and the under-five mortality rate in the short term. however, it was found that these relationships were not statistically significant at 95\% confidence level ( $p>0.05)$.

When the effects of economic crises on the under-five mortality rate are analyzed, according to the information in the Table 5, it was found out that the economic crisis of 1994 had a statistically significant adverse effect $(\mathrm{p}=0.22)$. But it was found that 2001 and 2009 crises did not have a significant effect ( $p>0.05$ ). From these results, it is understood that the 1994 economic crisis affected the under-five mortality rate significantly and negatively. There are many factors in the effects of economic crises on child health. One of these factors is malnutrition caused by crises, as expressed by many authors (Cader and Perera, 2011; Fernandez and Lopez-Calva, 2009; Paxson and Schady, 2004; Schady and Smitz, 2010). Because of the crises, families can reduce food quality and quantity and as a result, children are affected most. According to the data of TDHS (Turkey Demographic and Health Survey) 1993, 1998, 2003 and 2008, the percentage of malnutrition in the age group of under-five between 1994 and 1998 seems to be higher than the other periods on average (Hacettepe 
University Institute of Population Studies, 1994, 1999, 2003, 2009). In this context, it is considered that the economic crisis of 1994 may have a negative effect on the factors related to malnutrition of children and may have a negative impact on the under-five mortality rate. In addition, after the economic crisis of 1994, it is possible that families will have a negative impact on under-five deaths as a consequence of not resorting to a healthcare facility in their important health needs such as diarrhea, or taking care of them at home.

\section{Conclusions and Suggestions}

In this study, the relationship between macroeconomic factors such as real GDP, inflation and unemployment, and the rate of infant and under-five mortality within the context of the child health indicator and the impact of the crises on child health are examined. In this context, data from 1974-2015 were analyzed by ARDL bounds testing approach.

As a result of the study, it has been concluded that the relationship between infant mortality rate and under-five mortality rate, and macroeconomic factors (real GDP, inflation and unemployment) is procyclical in the long-term correct. That is, as income, inflation and unemployment increase, the infant mortality rate and under-five mortality rate are also increasing. Although the real GDP, inflation rate and unemployment rate increase in the longterm have negative effects in this study, it is found that just the increase in real GDP has a significant negative impact on the infant mortality rate and under-five mortality rate. These results support the theories that economic growth periods in terms of real GDP may have negative health effects (Gertham and Ruhm, 2006; Granados, 2005; Neumayer, 2004; Mattei et al., 2014; Ruhm, 2003).

The followings can be said for the reason for this procyclical relationship between real GDP and infant mortality rate and under-five mortality rate: due to the increasing demand for work and increased working hours in Turkey, especially in the times of economic growth, it is evaluated that the lack of sufficient time for the children to provide care to their children and the lack of adequate time-intensive activities such as meeting their health care needs and adequate nutrition may be the reason and, it is considered that the increase in income may have caused health hazard behaviors on the mother's side, especially for infant mortality rate affected more from maternal health. In the light of this evaluations, it is recommended to increase maternity leave and financial assistance to mothers for infants and to increase financial aids especially for under-five years.

It is concluded in this research that the 2001 economic crisis effected infant mortality rate 
significantly negative and the 2009 crisis effected infant mortality rate significantly positive in Turkey. In this context, it is recommended that public health expenditures should be increased during periods of economic crisis especially in order to prevent the health of the baby from being adversely affected and the maternity-leave hours of the working mothers be extended, the related legal limits should be extended and the postnatal infant follow-ups should be made more stringent. In the scope of the effects of economic crises in Turkey on the under-five mortality rate, it was concluded that only the 1994 economic crisis affected it significantly negative. Although there are many factors affecting the impacts of economic crises on child health, malnutrition due to the decrease in the quality and quantity of food and postponement of health services are important factors for child health. Therefore, it is important in order to prevent negative impacts by increasing food aid and support to poor families in times of crisis.

\section{References}

Borowy, I. (2011). Similar but different: Health and economic crisis in 1990s Cuba and Russia. Social Science \& Medicine, 72, 1489-1498. DOI 10.1016/j.socscimed.2011.03.008.

Bulutay, T. (1995). Employment, unemployment and wages in Turkey. Ankara: ILO, State Institute of Statistics.

Cader, A.A. and Perera, L. (2011). Understanding the impact of the economic crisis on child and maternal health among the poor: Opportunities for South Asia. ADBI Working Paper 293. Tokyo: Asian Development Bank Institute.

Christian, P. (2009). Impact of the economic crisis and increase in food prices on child mortality: Exploring nutritional pathways. The Journal of Nutrition, 140, 177-181. DOI 10.3945/jn.109.111708.

Ciftci, F. and Yildiz, R. (2015). The economic determinants of foreign direct investment: a time series analysis of the Turkish economy. Business and Economics Research Journal, 6(4), 71-95.

Cutler, D.M., Knaul, F., Lozano, R., Méndez, O. and Zurita, B. (2002). Financial crisis, health outcomes and aging: Mexico in the 1980s and 1990s. Journal of Public Economics, 84, 279-303. DOI 10.1016/S0047-2727(01)00127-X

Fernandez, A. and Lopez-Calva, L.F. (2009). The impact of the crisis on vulnerable populations: What do we know? Poverty, Human Development and MDGs Cluster, Regional Bureau for Latin America and The Caribbean, United Nations Development Programme, Crisis Update No. 5.

Gerdtham, Ulf-G. and Ruhm, C.J. (2006). Deaths rises in good economic times: Evidence from the OECD. Economics and Human Biology, 4, 298-316. DOI 10.1016/j.ehb.2006.04.001

Granados, J.A.T. (2005). Recessions and mortality in Spain, 1980-1997. European Journal of Population, 21, 393-422. DOI 10.1007/s10680-005-4767-9. 
Hacettepe University Institute of Population Studies. (1994). Turkey Demographic and Health Survey 1993. Ankara: Hacettepe Printing Office.

Hacettepe University Institute of Population Studies. (1999). Turkey Demographic and Health Survey 1998. Ankara: Hacettepe Printing Office.

Hacettepe University Institute of Population Studies. (2003). Turkey Demographic and Health Survey 2003. Ankara: Hacettepe Printing Office.

Hacettepe University Institute of Population Studies. (2009). Turkey Demographic and Health Survey 2008. Ankara: Hacettepe Printing Office.

HPC (Healthy Public Policy). (2011). Social environments and health. Concept paper. Edmonton: Alberta Health Services.

Lopes, R.P. (1934). The economic depression and public health. International Labour Review, 29, 784-811.

Mattei, G., Ferrari, S., Pingani, L. and Rigatelli, M. (2014). Short-term effects of the 2008 great recession on the health of the Italian population: An ecological study. Social Psychiatry and Psychiatric Epidemiology, 49, 851-858. DOI 10.1007/s00127-014-0818-z.

McClure, C.B., Valdimarsdóttir, U.A., Hauksdóttir, A. and Kawachi, I. (2012). Economic crisis and smoking behaviour: Prospective cohort study in Iceland. BMJ Open, 2:e001386. DOI 10.1136/bmjopen-2012-001386.

Menabde, N. (2009). Health policy in times of crisis: Challenge and opportunity. HPM Spotlight. $\quad$ Retrived $21 \quad$ February 2014, http://www.hpm.org/Downloads/HPM_SPOTLIGHTS/HPM_Spotlight_hp_in_times_of_cr isis_Dec_09.pdf

Neumayer, E. (2004). Recessions lower (some) mortality rates: Evidence from Germany. Social Science \& Medicine, 58, 1037-1047. DOI 10.1016/s0277-9536(03)00276-4.

Paxson, C. and Schady, N. (2004). Child health and the 1988-1992 economic crisis in Peru. World Bank Policy Research Working Paper 3260.

Pesaran, M.H., Shin, Y. and Smith, R.J. (2001). Bounds testing approaches to the analysis of level relationships. Journal of Applied Econometrics, 16(3), 289-326. DOI 10.1002/jae.616.

Riva, M., Bambra, C., Easton, S. and Curtis, S. (2011). Hard times or good times? Inequalities in the health effects of economic change. International Journal of Public Health, 56, 3-5. DOI 10.1007/s00038-010-0220-x.

Ruhm, C.J. (2003). Good times make you sick. Journal of Health Economics, 22, 637-658. DOI 10.1016/S0167-6296(03)00041-9.

Schady, N. and Smitz, M. (2010). Aggregate economic shocks and infant mortality: New evidence for middle-income countries. Economic Letters, 108, 145-148. DOI 10.1016/j.econlet.2010.03.017.

Stuckler, D., Basu, S., Suhrcke, M., Coutts, A. and McKee, M. (2011). Effects of the 2008 recession on health: A first look at European data. Lancet, 378, 124-125. DOI 10.1016/S0140-6736(11)61079-9.

Tangcharoensathien, V., Harnvoravongchai, P., Pitayarangsarit, S. and Kasemsup, V. (2000). Health impacts of rapid economic changes in Thailand. Social Science \& Medicine, 51(6), 
789-907. DOI 10.1016/s0277-9536(00)00061-7.

Thomas, S., Keegan, C., Barry, S., Layte, R., Jowett, M. and Normand, C. (2013). A framework for assessing health system resilience in an economic crisis: Ireland as a test case. BMC Health Services Research, 13:450. DOI 10.1186/1472-6963-13-450.

TurkStat. (2016). Labor statistics. Retrived 12 May 2016, http://www.tuik.gov.tr/PreTablo.do?alt_id=1007

UNICEF (United Nations Children's Found). (1991). The impact of economic crisis and adjustment on health care in Mexico. Unicef İnternational Child Development Centre, Innocenti Ocasional Papers, No: 13.

World Bank. (2016). Country: turkey. Retrived 12 May 2016, http://data.worldbank.org/country/turkey?view=chart 